OPEN ACCESS

Edited by:

Kai He,

Lanzhou University, China

Reviewed by:

Frantisek Baluska,

University of Bonn, Germany

Tamara Pecenkova,

Institute of Experimental Botany

(ASCR), Czechia

*Correspondence:

Wenzhi Lan

lanw@nju.edu.cn

Sheng Luan

sluan@berkeley.edu

Lei Yang

leiyang@nju.edu.cn

${ }^{\dagger}$ These authors have contributed equally to this work.

Specialty section:

This article was submitted to

Plant Traffic and Transport,

a section of the journal

Frontiers in Plant Science

Received: 22 July 2017 Accepted: 25 September 2017 Published: 13 October 2017

Citation:

Yu J, Ge H, Wang X, Tang R,

Wang Y, Zhao F, Lan W, Luan S and Yang $L$ (2017) Overexpression of Pyrabactin Resistance-Like Abscisic Acid Receptors Enhances Drought, Osmotic, and Cold Tolerance in Transgenic Poplars.

Front. Plant Sci. 8:1752.

doi: 10.3389/fpls.2017.01752

\section{Overexpression of Pyrabactin Resistance-Like Abscisic Acid Receptors Enhances Drought, Osmotic, and Cold Tolerance in Transgenic Poplars}

\author{
Jingling Yu' ${ }^{1+}$, Haiman $\mathrm{Ge}^{1+}$, Xiaokun Wang ${ }^{1}$, Renjie Tang ${ }^{2}$, Yuan Wang ${ }^{1}$, Fugeng Zhao', \\ Wenzhi Lan ${ }^{1 *}$, Sheng Luan ${ }^{1,2 *}$ and Lei Yang ${ }^{1 *}$ \\ 1 State Key Laboratory for Pharmaceutical Biotechnology, NJU-NFU Joint Institute for Plant Molecular Biology, College of \\ Life Sciences, Nanjing University, Nanjing, China, ${ }^{2}$ Department of Plant and Microbial Biology, University of California, \\ Berkeley, Berkeley, CA, United States
}

Abscisic acid (ABA) has been known participate in a wider range of adaptive responses to diverse environmental abiotic stresses such as drought, osmosis, and low temperatures. ABA signaling is initiated by its receptors PYR/PYL/RCARs, a type of soluble proteins with a conserved START domain which can bind ABA and trigger the downstream pathway. Previously, we discovered that poplar (Populus trichocarpa) genome encodes 14 PYR/PYL/RCAR orthologs (PtPYRLs), and two of them, PtPYRL1 and PtPYRL5 have been functionally characterized to positively regulate drought tolerance. However, the physiological function of these ABA receptors in poplar remains uncharacterized. Here, we generated transgenic poplar plants overexpressing PtPYRL1 and PtPYRL5 and found that they exhibited more vigorous growth and produced greater biomass when exposed to drought stress. The improved drought tolerance was positively correlated with the key physiological responses dictated by the ABA signaling pathway, including increase in stomatal closure and decrease in leaf water loss. Further analyses revealed that overexpression lines showed improved capacity in scavenging reactive oxygen species and enhanced the activation of antioxidant enzymes under drought stress. Moreover, overexpression of PtPYRL1 or PtPYRL5 significantly increased the poplar resistance to osmotic and cold stresses. In summary, our results suggest that constitutive expression of PtPYRL 1 and PtPYRL5 significantly enhances the resistance to drought, osmotic and cold stresses by positively regulating ABA signaling in poplar.

Keywords: Populus, ABA receptor, drought, cold stress, osmotic stress, resistance

\section{INTRODUCTION}

Plants, as sessile organisms, have evolved sophisticated developmental and physiological strategies to adapt to the unfavorable and changing environments such as drought, high salinity, and temperature fluctuations. Drought has particularly been considered as one of the most serious natural hazards for agriculture due to the increasing water scarcity (Liu et al., 2015). Numerous 
studies showed that drought stress exerts many negative effects on plant growth, photosynthesis, biomass accumulation, and ecosystem carbon cycling (Liu et al., 2011; Zhou et al., 2015). Desiccation results in the production of reactive oxygen species (ROS), the production of which, in turn, serves as an important indicator to multiple abiotic stresses (Apel and Hirt, 2004; Contreras-Porcia et al., 2011). Normally, ROS are rapidly scavenged as a result of the activation of an efficient antioxidant system involved in various drought-induced signaling pathways, which are modulated by abscisic acid (ABA) (Jiang and Zhang, 2002; Contreras-Porcia et al., 2011).

The physiological functions of ABA has been extensively investigated in plants since it was identified in the $1960 \mathrm{~s}$ as an endogenous plant hormone which regulates many essential processes, including seed germination, stomatal movement, plant development and adaptive responses, to multiple environmental stresses, such as drought, extreme temperatures, hyperosmolarity, and salinity (Finkelstein et al., 2002; Park et al., 2009). Many key components in ABA signaling pathway have been identified at the molecular level (Finkelstein et al., 2002), including ABA receptors (Shen et al., 2006; Liu et al., 2007; Pandey et al., 2009), the group A type 2 C protein phosphatases (PP2Cs) that negatively regulate ABA signaling at an early step in the pathway (Allen et al., 1999), the SnRK2 kinases that are positive regulators (Mustilli et al., 2002; Yoshida et al., 2002; Fujii et al., 2007), transcription factors (Seki et al., 2002; Himmelbach et al., 2003) and ion channels (Lee et al., 2009).

As the initial sensor of ABA signaling pathway, 14 genes designated as Pyr1 and Pyl1-Pyl13 (for PYR1-Like) have been identified in the Arabidopsis genome and encode proteins belonging to members of the cyclase subfamily of the START/Bet v I superfamily, which share a conserved hydrophobic ligandbinding pocket (Ma et al., 2009; Park et al., 2009). In presence of $\mathrm{ABA}$, these proteins perceive $\mathrm{ABA}$, then undergo conformation changes, and subsequently bind to clade A subfamily of PP2Cs, thus de-repressing the inactivation of the downstream SNF1related protein kinase 2 (SnRK2) kinases. The PYR/PYL/RCARPP2C-SnRK2 signaling module is conserved across land plants.

Genetic evidence suggested that higher-order mutants lacking multiple ABA receptors in Arabidopsis (Pyr 1;Pyl1;Pyl2;Pyl4;Pyl5;Pyl8) exhibit severe ABA insensitive phenotypes, establishing their critical physiological roles in ABA signaling (Gonzalez-Guzman et al., 2012). PYL5 over-expression in Arabidopsis led to a globally enhanced response to ABA and enhanced drought resistance (Santiago et al., 2009). Constitutive overexpression of PYL8/RCAR3 confers ABA hypersensitivity in Arabidopsis seeds (Saavedra et al., 2010). Overexpression of NtPYL4 in tobacco hairy roots resulted in a reprogramming of the cellular metabolism that is represented by a decreased alkaloid accumulation and conferred ABA sensitivity to the production of alkaloids (Lackman et al., 2011).

Tree species in the genus Populus spp., commonly known as poplars, aspens, and cottonwoods, are widespread in the northern hemisphere with nutrient-poor environments, and are increasingly important for bioenergy, wood products, and environmental services (Doty et al., 2016). Most of the poplar cultivation and distribution area are in the desolate lands on the earth where it is usually cold and dry in winter, causing the restriction of poplar forestry. Therefore, it is very critical to improve the resistance of poplars to abiotic stresses, including drought-resistance and cold-resistance. We have previously shown that PtPYRL1 and PtPYRL5 (poplar AtPYR1-like 1 and 5) physically interacted with PP2Cs, which interacted with SnRK2 kinase, suggesting they might act as the $\mathrm{ABA}$ receptors in mediating $\mathrm{ABA}$ signal transduction through phosphorylation and dephosphorylation (Yu et al., 2016). Furthermore, overexpression of PtPYRL1 or PtPYRL5 in Arabidopsis enhanced ABA sensitivity and drought-resistance. However, it is still unknown if they also play a similar function in poplars which protect against drought stress. Here, we report that the overexpression of PtPYRL1 and PtPYRL5 in poplar enhances resistance to drought, osmosis, and cold, the abiotic stresses that poplar frequently encounters. Our results also provide a potential biotechnological tool in engineering stress-resistant poplar cultivars.

\section{MATERIALS AND METHODS}

\section{Plant Materials and Growth Conditions}

The sterile wild-type and transgenic hybrid poplar (Populus davidiana $\times$ Populus bolleana) were amplified by micropropagation with leaf bud explants and kept under a 16h-light/8-h-dark photoperiod $\left(120 \mu \mathrm{mol} \cdot \mathrm{m}^{-2} \cdot \mathrm{s}^{-1}\right)$ at $21-24^{\circ} \mathrm{C}$. The plantlets were sub-cultured onto fresh 1/2 Murashige and Skoog (MS) medium supplemented with $0.1 \mathrm{mg} \cdot \mathrm{L}^{-1}$ naphthaleneacetic acid (NAA) and $1 \%(w / v)$ agar. Two-week-old wild type (WT) or transgenic hybrid poplars with new roots were transferred to $7.5 \mathrm{~cm}$-width pots containing nutrient soil. The plants were grown in greenhouse under a 16-h-light/8-h-dark $\left(120 \mu \mathrm{mol} \cdot \mathrm{m}^{-2} \cdot \mathrm{s}^{-1}\right)$ at $21-24^{\circ} \mathrm{C}$.

\section{Poplar Transformation}

To construct the pCAMBIA1301S2-PtPYRL1 (or PtPYRL5) plasmid, the entire coding region of PtPYRL1 (or PtPYRL5) was amplified by PCR with Xba I-Sal I (or BamH I-Sal I) linker primers and cloned into modified pCAMBIA1301S2 with the $2 \times \mathrm{CaMV} 35 \mathrm{~S}$ promoter via the Xba I-Sal I (or BamH I-Sal I) site (Supplementary Figure S1). The hybrid poplars (Populus davidiana $\times$ Populus bolleana) were transformed using Agrobacterium tumefaciens (EHA105 strain) infection method. Briefly, leave explants excised from 1- to 2-month-old were inoculated in the EHA105 culture resuspended with liquid MS for $10 \mathrm{~min}$ and then were plated on solid MS medium containing $0.4 \mathrm{mg} \cdot \mathrm{L}^{-1}$ 6-BA, $0.1 \mathrm{mg} \cdot \mathrm{L}^{-1} \mathrm{NAA}$ and $0.01 \mathrm{mg} \cdot \mathrm{L}^{-1} \mathrm{TDZ}$. After 2 days of co-cultivation with Agrobacterium, the explants were transferred onto fresh MS medium containing $400 \mathrm{mg} \cdot \mathrm{L}^{-1}$ timentin, and $10 \mathrm{mg} \cdot \mathrm{L}^{-1}$ hygromycin for selective regeneration. When regenerated shoots reached $1 \mathrm{~cm}$ tall, they were excised and placed on rooting medium. Then, the rooted seedlings were transferred into soil and grown in the greenhouse. The presence of transgene was verified by PCR from genomic DNA, using primers specific for P35S and PtPYRL1-RT-R or PtPYRL5-RT-R. 


\section{Histochemical GUS Analysis}

Detection of $\beta$-glucuronidase (GUS) activity was performed as described by Jefferson et al. (1987) with some modifications: leaf explants were incubated in GUS assay buffer $(50 \mathrm{mM}$ sodium phosphate, $\mathrm{pH} 7.0,0.1 \%$ [v/v] Triton X-100, $0.5 \mathrm{mM}$ ferricyanide, $0.5 \mathrm{mM}$ ferrocyanide, and $2 \mathrm{mM}$ 5-bromo-4-chloro-3-indolyl$\beta$-D-glucuronide) for $12 \mathrm{~h}$ at $37^{\circ} \mathrm{C}$. Then the plant tissues were decolorized in $75 \%$ ethanol for three times. The samples were photographed after treatment.

\section{Quantitative Real-time PCR Analysis}

Total RNA was extracted from various samples using TRIzol reagent (Invitrogen, Carlsbad, CA, United States), which was sequentially treated with DNase I (Invitrogen) and reverse transcribed by M-MLV reverse transcriptase (Promega). In semiquantitative RT-PCR and qRT-PCR assays, the poplar elongation factor gene $E F 1 \beta$ was used as an internal reference. qRT-PCR was performed with a CFX Connect Real-Time System (Bio-Rad). The relative expression of series indicated genes was calculated based on the comparative threshold cycle method using EF1 $\beta$ as a control and normalized to the WT hybrid poplars (under normal conditions). All primers used in this study were listed in Supplementary Table S1.

\section{Drought-Rehydration Experiments}

Two-week-old WT or transgenic poplars were transplanted to each $7.5 \mathrm{~cm}$-width pot containing $50 \mathrm{~g}$ nutrient soil for greenhouse cultivation. We chose the 2-month-old WT or transgenic poplar seedlings with the same height to perform the drought and rehydration experiments. As the control, half of WT and transgenic poplar seedlings were normally watered, and the rest of these seedlings were not watered. After 1 week, the plantlets were watered again. After 3 days, the re-watered plants were photographed.

\section{Water Potential Determination}

Leaf water potential was measured on the same location of the blade with a WP4-T Dew point PotentiaMeter (Decagon Devices, Inc., United States). Five individual plants from WT or different transgenic poplars were measured after drought treatment for 5 days.

\section{Measurement of Contents of $\mathrm{H}_{2} \mathrm{O}_{2}$, MDA, and Proline}

$\mathrm{H}_{2} \mathrm{O}_{2}$ in fresh leaves was analyzed using the method reported by $\mathrm{Hu}$ et al. (2012). The absorbance was recorded at $390 \mathrm{~nm}$ with the spectrophotometer (Biomate 3S, Thermo). Malondialdehyde (MDA) content was quantified using the method reported by Heath and Packer (1968), which is related with the level of lipid peroxidation in the leaves. The absorbance was read at 532 and $600 \mathrm{~nm}$ by the spectrophotometer (Biomate 3S, Thermo) with thiobarbituric acid (1\%) in $20 \%$ trichloroacetic acid as control. The Proline content in leaves was quantified using the method by Bates et al. (1973). The absorbance was measured spectrophotometrically (Biomate $3 \mathrm{~S}$, Thermo) at $520 \mathrm{~nm}$ and toluene was used as blank.

\section{Extraction and Assay of Antioxidant Enzymes}

Fresh leaves $(0.5 \mathrm{~g} / \mathrm{sample})$ were homogenized in presence of $100 \mathrm{mM}$ Tris- $\mathrm{HCl}$ (5.0 ml, pH 7.5), $3.0 \mathrm{mM} \beta$-mercaptoethanol, $1.0 \mathrm{mM}$ EDTA (ethylenediaminetetraacetic acid), and 1.5\% polyvinylpyrrolidone-40. The mixture was better supplemented with serine and cysteine proteinase inhibitors $[1.0 \mathrm{mM}$ phenylmethanesulfonyl fluoride (PMSF) $+1.0 \mu \mathrm{g} \cdot \mathrm{mL}^{-1}$ aprotinin]. The homogenate was centrifuged at $10,000 \times g$ for $15 \mathrm{~min}\left(4^{\circ} \mathrm{C}\right)$ after the filtration through cheese cloth. The supernatants were collected and served as the crude enzyme for determination of SOD (EC1.15.1.1), CAT (EC1.11.1.6), and POD (EC 1.11.1.7) activities. For the determination of APX activity, leaf sample was separately grounded in a homogenizing medium supplemented with $2.0 \mathrm{mM}$ ascorbic acid (AsA) to maintain the enzyme stability. SOD activity was analyzed after the photoreduction of nitroblue tetrazolium (NBT) according to the method of Giannopolitis and Ries (1977). The absorbance was recorded spectrophotometrically (Biomate 3S, Thermo) at $560 \mathrm{~nm}$. One unit of SOD is the quantity of protein that hampers $50 \%$ photoreduction of NBT and the activity was expressed as enzyme unit (EU) $\cdot \mathrm{mg}^{-1}$ protein. The method of Chance and Maehly (1955) was employed to analyze CAT activity. The absorbance was read at $240 \mathrm{~nm}$ through a UVVisible spectrophotometer (Biomate 3S, Thermo) and EU. $\mathrm{mg}^{-1}$ protein represented the CAT activity. The method of Nakano and Asada (1981) was used for the APX activity (EC1.11.1.11) measurement. The absorbance was recorded at $290 \mathrm{~nm}$ each $30 \mathrm{~s}$ for $3 \mathrm{~min}$ spectrophotometrically (Biomate $3 \mathrm{~S}$, Thermo). The POD activity was determined by examining the absorbance of reaction buffer at $420 \mathrm{~nm}$ based on guaiacol oxidation (Maehly and Chance, 1954). APX activity was calculated by

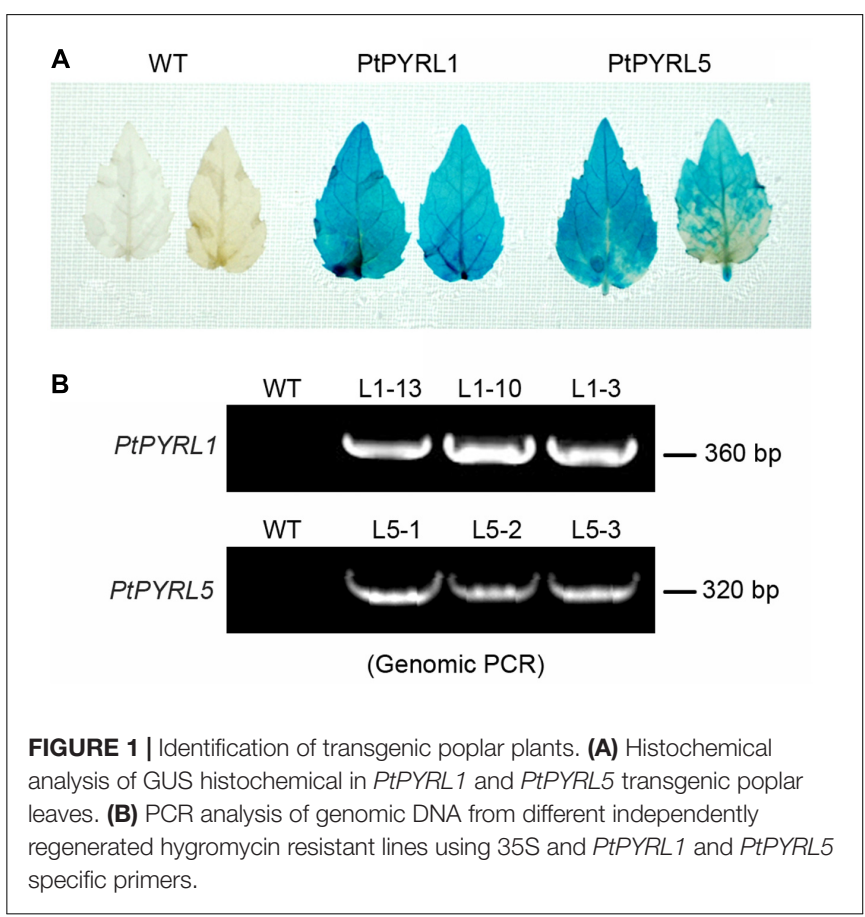


the consumption rate of ASC using the ASC extinction molar coefficient $\left(e=2.8 \mathrm{mM}^{-1} \cdot \mathrm{cm}^{-1}\right)$. APX activity was expressed with EU.mg ${ }^{-1}$ protein. One unit of APX is the quantity of protein used to break down $1.0 \mu \mathrm{mol}$ of substrate per min at $25^{\circ} \mathrm{C}$. The activity of GR (EC 1.6.4.2) and GPX (EC 1.11.1.9) was determined using GR Assay Kit (S0055, Beyotime, China) and Total GPX Assay Kit (S0058, Beyotime, China), respectively, according to the manufacturer's instructions. The absorbance was read at $340 \mathrm{~nm}$ with spectrophotometer (Biomate 3S, Thermo). GR activity was expressed as $\mu$ mol NADPH oxidized $\mathrm{min}^{-1}$ (EU. $\mathrm{mg}^{-1}$ protein) (Carlberg and Mannervik, 1985). The GPX activity was calculated by measuring the reduction of $\mathrm{NADPH}$ to $\mathrm{NADP}^{+}$at $340 \mathrm{~nm}$ of absorbance.

\section{Analysis of Relative Water Content (RWC)}

The extent of desiccation in WT and transgenic poplars aboveground part was indicated with RWC (\%) following the formula RWC $\%=\left(W_{\mathrm{de}}-W_{\mathrm{dr}}\right) /\left(W_{\mathrm{f}}-W_{\mathrm{dr}}\right) \times 100$, where $W_{\mathrm{f}}$ is the wet weight of fully hydrated aboveground part, $W_{\mathrm{de}}$ is the dehydrated weight after desiccation for a period of time, and $W_{\mathrm{dr}}$ is the dry weight determined after $48 \mathrm{~h}$ of drying at $80^{\circ} \mathrm{C}$. Through this, the RWC reflects the extent of desiccation, with a fully hydrated shoot having a RWC of $100 \%$ and a fully dehydrated shoot having a RWC close to $0 \%$. A lower RWC indicates higher desiccation.

\section{Stomatal Aperture Measurements}

To measure stomatal aperture in response to ABA, epidermal peels of the leaves in the same location were floated on a stomatal opening medium containing $50 \mathrm{mM} \mathrm{KCl,} 10 \mathrm{mM}$ MES- $\mathrm{KOH}(\mathrm{pH}$ 6.15), and $0.1 \mathrm{mM} \mathrm{CaCl}_{2}$ and incubated in a growth chamber under white light $\left(150 \mu \mathrm{mol} \cdot \mathrm{m}^{-2} \cdot \mathrm{s}^{-1}\right)$ for $2 \mathrm{~h}$. The epidermal strips were transferred to the opening medium with 0 or $20 \mu \mathrm{M}$ $\mathrm{ABA}$ and incubated for a further $2 \mathrm{~h}$ before stomatal apertures were measured.

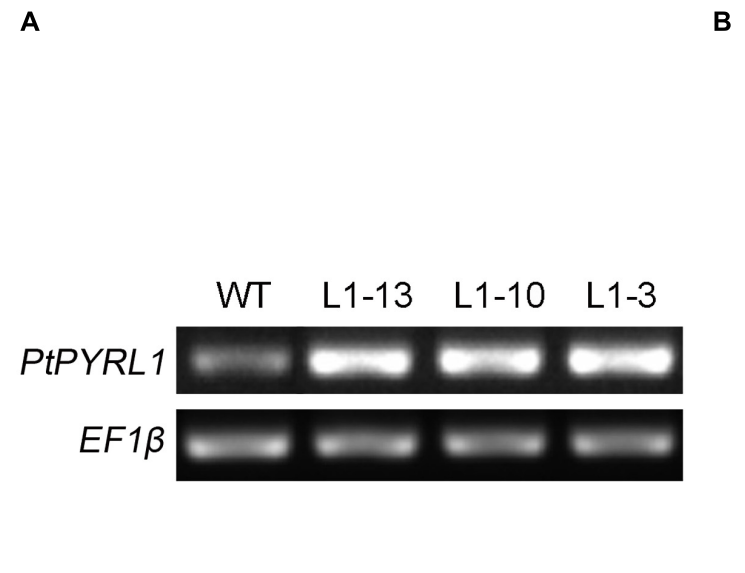

C

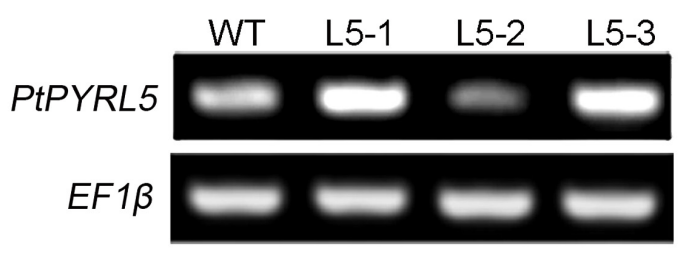

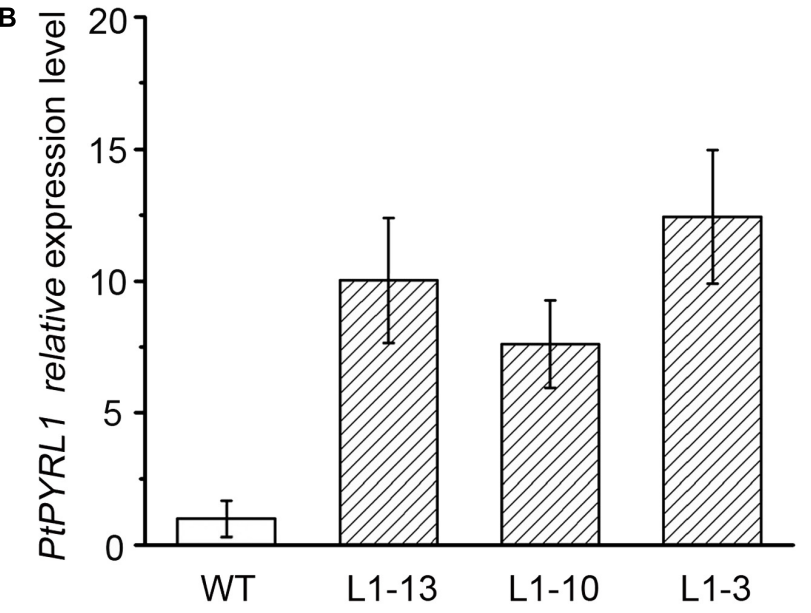

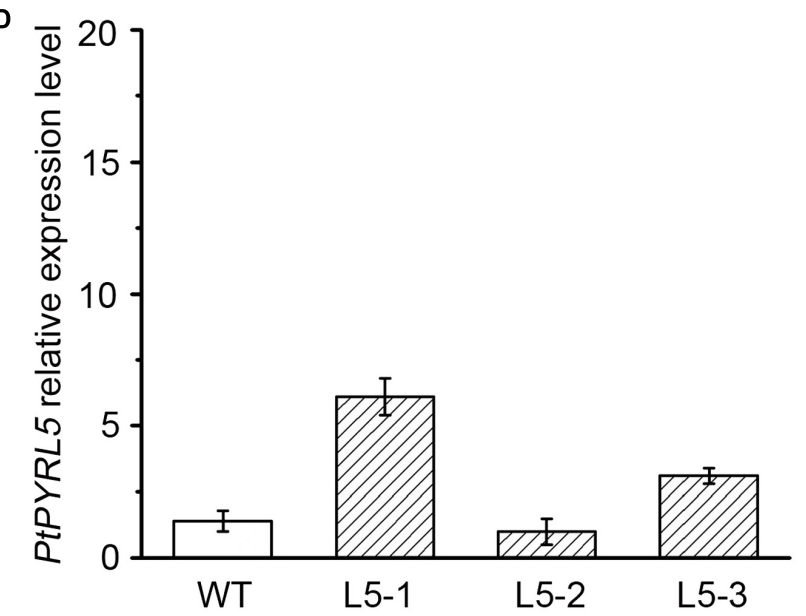

FIGURE 2 | Expression of PtPYRL1 or PtPYRL5 in wild type (WT) and transgenic hybrid poplars. Expression of PtPYRL1 (A) or PtPYRL5 (C) in 2-month-old WT and transgenic hybrid poplars (L1-13, L1-10, and L1-3) grown at normal medium. The level was detected using gene-specific primers after 26 PCR cycles. EF1 $\beta$ was used as endogenous control in all cDNA samples. Relative levels of PtPYRL1 transcripts (B) or PtPYRL5 transcripts (D) in three transgenic lines by qRT-PCR. Total RNA was isolated from 2-month-old leaves grown at normal medium. The relative expression level was calculated as the ratio of PtPYRL level to endogenous control EF1ß level. 


\section{Hyperosmotic Stress Treatment}

The $5 \mathrm{~cm}$ apical shoot segments of WT and transgenic poplars were transferred into the $1 / 2$ solid Murashige and Skoog (MS) medium containing $0.1 \mathrm{mg} \cdot \mathrm{L}^{-1}$ naphthaleneacetic acid and $1 \%$ (w/v) agar supplemented with 0,200 , or $300 \mathrm{mM}$ mannitol. The photos were taken at the 30th day after mannitol treatment. The experiments were repeated three times.

\section{$\mathrm{H}_{2} \mathrm{O}_{2}$ Staining}

$\mathrm{H}_{2} \mathrm{O}_{2}$ in leaves was visualized by 3,3-diaminobenzidine (DAB). Populus leaves were cut at the leaf base and infiltrated in $1 \mathrm{mg} / \mathrm{mL}$ DAB solution (50 mM Tris-HAC, pH 5.0) for $2-8 \mathrm{~h}$. Samples were then decolorized in $95 \%$ ethanol at $80^{\circ} \mathrm{C}$ for $2 \mathrm{~h}$. Brown flecks indicate the accumulation of $\mathrm{H}_{2} \mathrm{O}_{2}$ (Yang et al., 2004). The leaves were observed and photographed under stereomicroscope.

\section{Statistical Analysis}

The experiments were repeated three times and all comparisons of average values were analyzed using one-way ANOVA test. Post hoc comparisons were performed by applying least significant difference test. Significant differences were indicated with the threshold of $P<0.05$.

\section{RESULTS}

\section{Molecular Characterization of the Transgenic PtPYRLs Poplar Plants}

To obtain transgenic poplar lines that overexpress the ABA receptors PtPYRL1 and PtPYRL5 genes under the control of the CaMV 35 S promoter were introduced into the leaf explants from
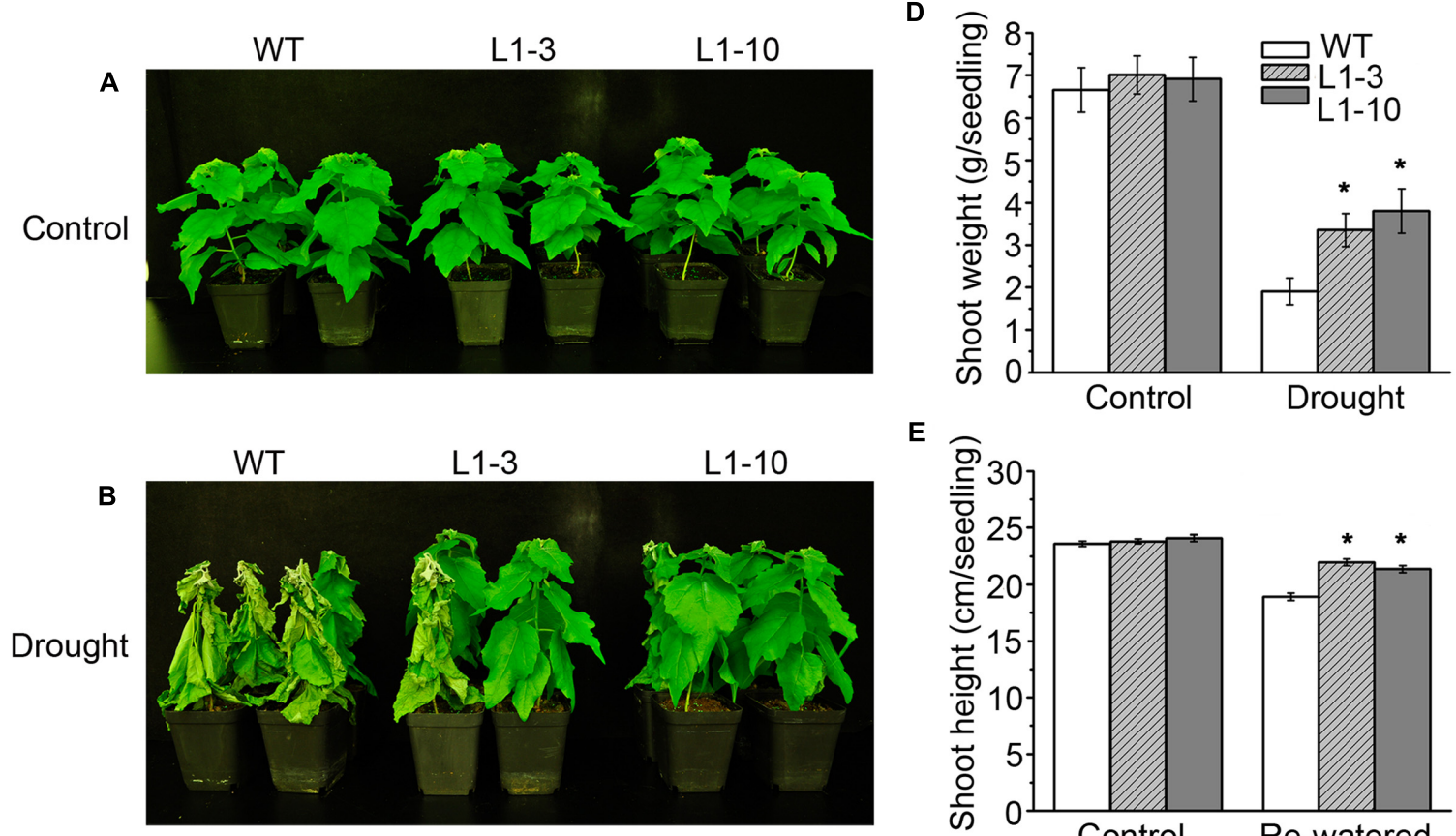

E
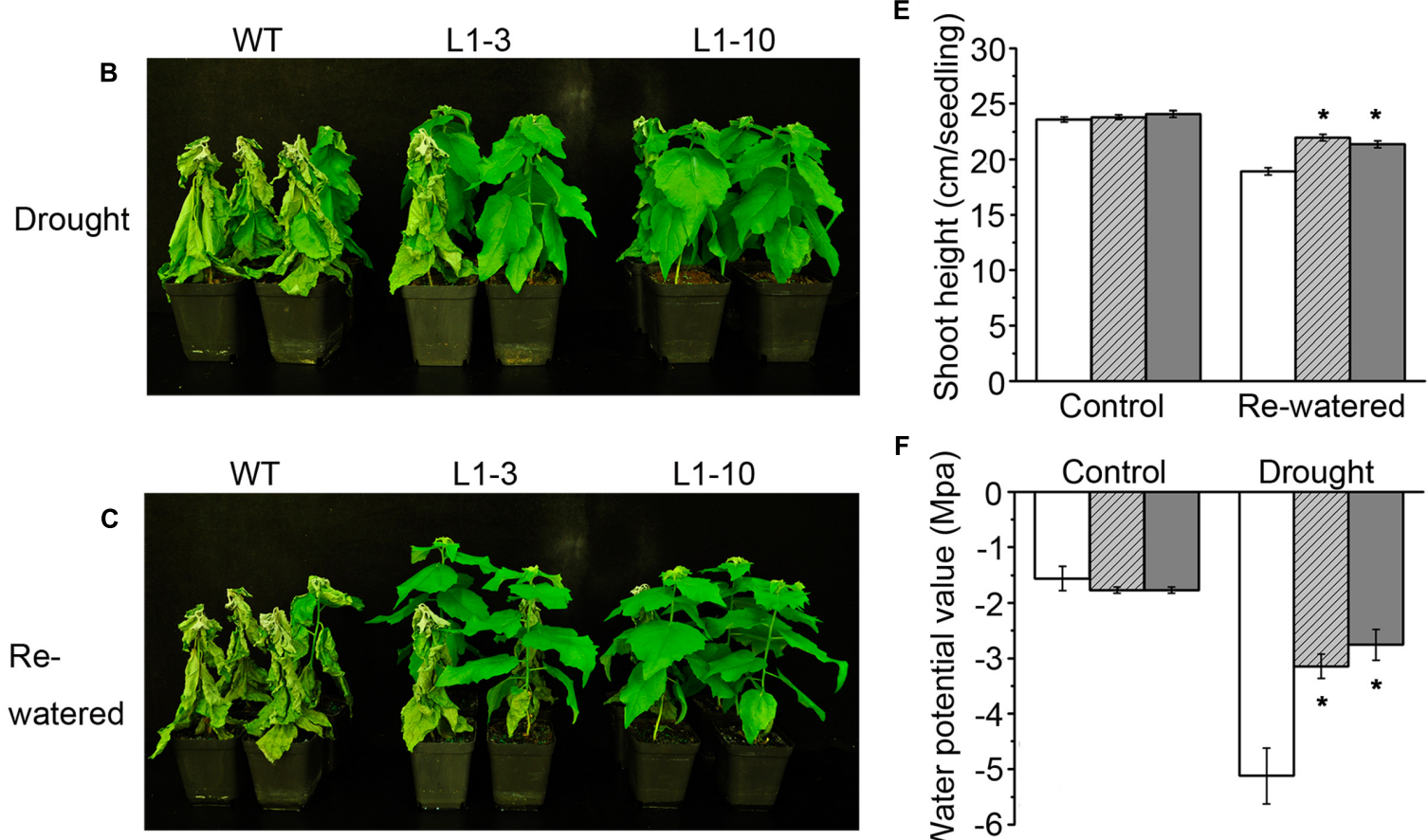

F

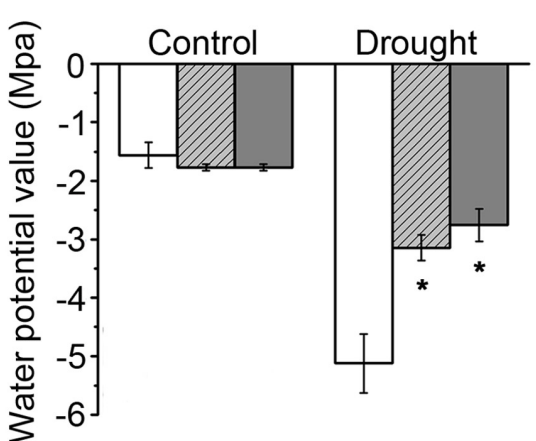

FIGURE 3 | Overexpression of poplar ABA receptor PtPYRL1 in poplars enhanced drought-stress resistance. (A) Two-month-old WT (non-transgenic hybrid poplars) and transgenic poplars (L1-3 and L1-10) were cultured in the greenhouse with normal watering. (B) WT and transgenic hybrid poplars were not watered for 5 days. (C) After drought, WT and transgenic hybrid poplars were then re-watered for 3 days. The shoot weight after drought stress treatment (D), shoot height after re-watered for 3 days $\mathbf{( E )}$, water potential value (F) of WT and transgenic hybrid poplars were measured. Values are means \pm standard deviation (SD) (one-way ANOVA test; ${ }^{*} P<0.05$ as compared to WT). 
a hybrid poplar cultivar (Populus davidiana $\times$ Populus bolleana), respectively. After cultured in the medium containing timentin and hygromycin, shoots were regenerated from some transfected explants (Supplementary Figure S2A). Partial regenerated shoots formed roots when they were placed on rooting medium (Supplementary Figure S2B), and these rooted plantlets were selected to analyze $35 S$-PtPYRL1 or 35S-PtPYRL5 insertion by PCR analysis of genomic DNA. A reporter gene encoding GUS was co-transferred into the leaf explants via the same vector, to authenticate the transgene expression in the putative transgenic lines. The GUS staining analysis revealed that all rooted seedlings expressed GUS activity properly (Figure 1A), confirming the integration and expression of the transgene in the genome of the transformants (Figure 1B). More than 10 independent lines were obtained for each of transgenes, including the lines L1-3, L1-10, and L1-13 expressing PtPYRL1, and the lines L5-1, L5-2, and L5-3 expressing PtPYRL5 (Figure 1B). After the rooted seedlings were transferred into soil, the survival seedlings were selected for further analysis of the differential expression levels of PtPYRLs by RT-PCR (Figures 2A,C) and qRT-PCR (Figures 2B,D). Among of them, Lines L1-3, L1-10, and L1-13 had over eightfold increment of the relative expression level of PtPYRL1 than in WT (Figure 2B), and lines L5-1 and L5-3 had over threefold increment of the relative expression level of PtPYRL5 compared with WT (Figure 2D). Thus, two lines with high level of PtPYRL1 (L1-3 and L1-10) or of PtPYRL5 (L5-1 and L5-3) were used for subsequent physiological analysis.

\section{Overexpression of Poplar ABA Receptors Enhanced Drought Tolerance in Transgenic Poplar Plants}

To investigate the role of PtPYRLs in drought tolerance, 2-month-old wild-type, PtPYRL1 transgenic plants (L1-3 and L1-10), and PtPYRL5 transgenic plants (L5-1 and L5-3) were subjected to water withhold for 5 days and then re-watered for 3 days. After 5 days of water deprivation, wild-type plants began to wilt, while most of transgenic plants remained fresh and alive (Figure 3B), similar to those grown under the watering condition (Figure 3A). When plants were re-watered for 3 days,
A

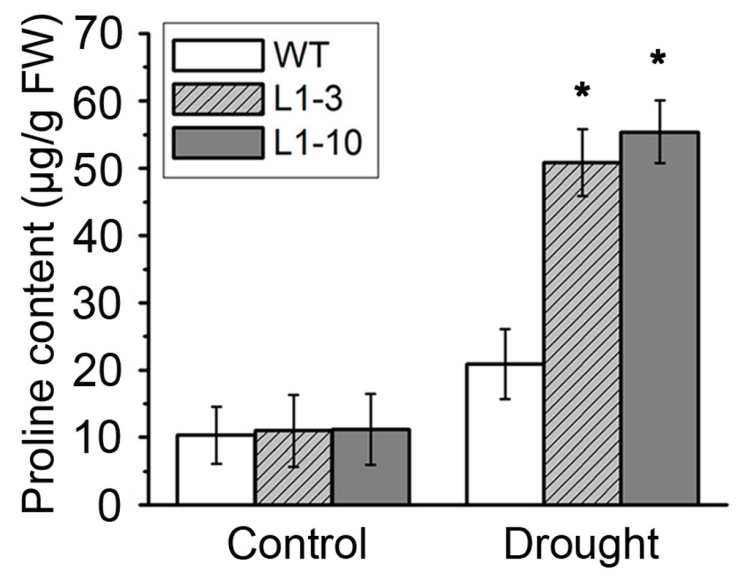

C

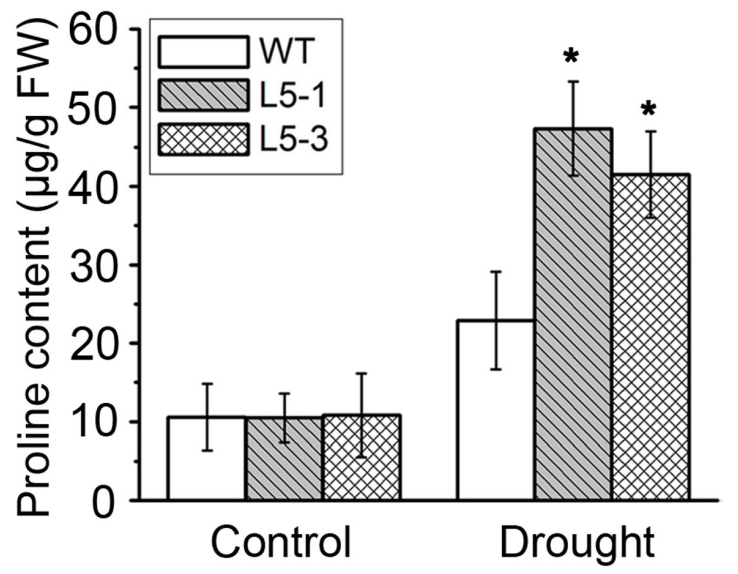

B

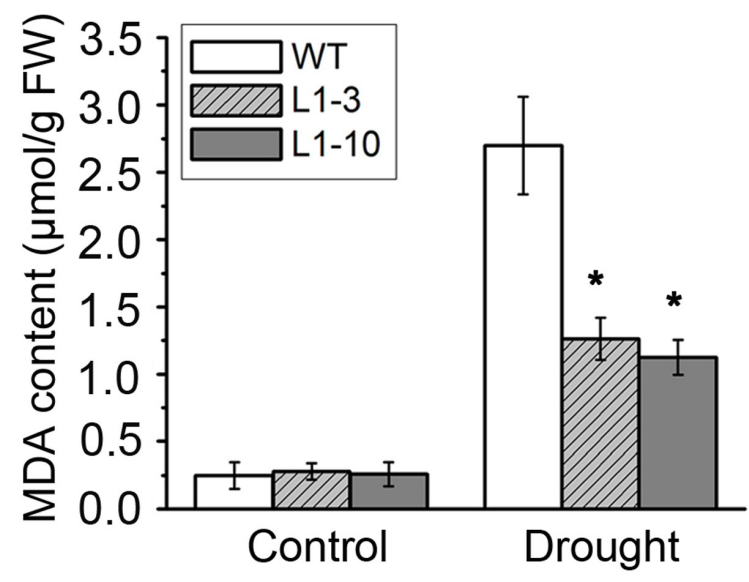

D

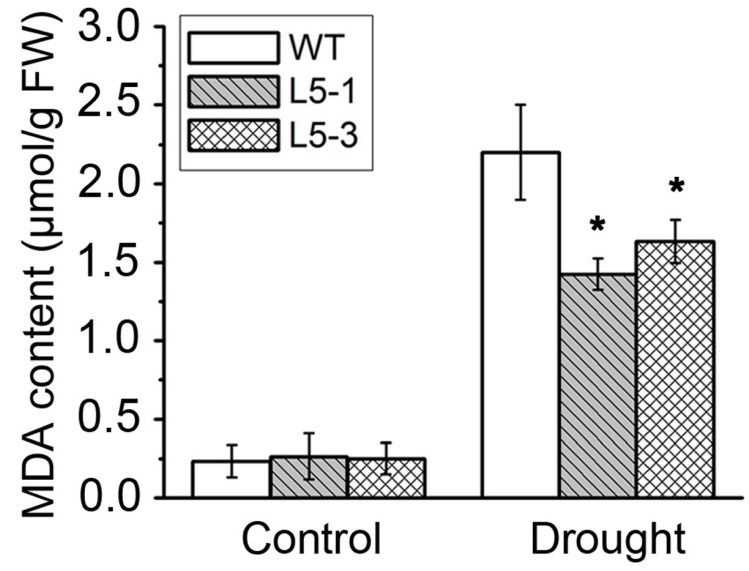

FIGURE 4 | Proline (A,C) and MDA (B,D) contents were measured in WT and PtPYRL1 or PtPYRL5 transgenic hybrid poplars after drought treatment. Values are means \pm SD (one-way ANOVA test; ${ }^{*} P<0.05$ as compared to WT). 


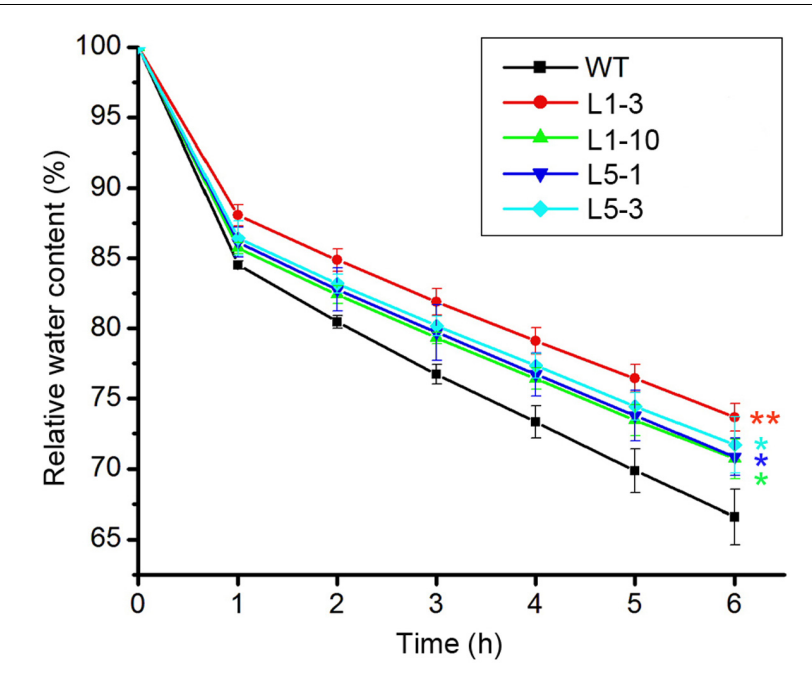

FIGURE 5 | Relative water content (RWC) of WT and PtPYRL1, PtPYRL5 overexpressing poplars after exposure in the air. RWC during a 6-h period from the detached shoot of the WT, PtPYRL1- and PtPYRL5-overexpressing hybrid poplars. Each value is the mean $\pm S D$ of three biological

determinations. One-way ANOVA test was used to compare the RWC of each transgenic poplar with those of the WT (with significant differences at ${ }^{*} P<0.05$ as compared to WT; ${ }^{* *} P<0.01$ as compared to WT).

WT became wilted permanently and eventually died, whereas transgenic plants showed less damaged and most of them recovered growth (Figure 3C). Similarly, PtPYRL5 transgenic plants [L5-1 and L5-3 and another two PtPYRL1 transgenic lines (L1-8 and L1-5)] displayed a healthier growth compared with the WT after rewatering (Supplementary Figures S3A-C). Furthermore, transgenic poplars overexpressing PtPYRL1 or PtPYRL5 showed more shoot biomass (Figure 3D and Supplementary Figures S3D, S4D) and shoot height (Figure 3E and Supplementary Figures S3E, S4E) than WT. They also had higher leaf water potential $\Psi$ than WT (Figure $3 \mathrm{~F}$ and Supplementary Figures S3F, S4F), indicating the leaves of transgenic lines retained more water during the stress.

Drought stress severely impairs the cellular lipid structure and function in tree species (Štajner et al., 2011), and thus the corresponding products proline and MDA were measured in these poplars. Though the proline and MDA contents in both WT and transgenic poplars were increased after drought stress treatment, the transgenic poplars contained higher proline level (Figures 4A,C) and less MDA content (Figures 4B,D) than WT. It is noteworthy that the changes of biomass, water potential, proline, and MDA in the transgenic PtPYRL5 lines (L5-1 and L5-3) were less significant than the transgenic PtPYRL1 lines (L1-3 and L1-10), suggesting that PtPYRL1 may be more potent than PtPYL5 in inducing the downstream protective responses. Moreover, relative water content (RWC) of detached leaves was higher from transgenic PtPYRL1 lines (L1-3 and L1-10) than from WT plants after exposed in air for $6 \mathrm{~h}$ (Figure 5). Taken together, these results indicated that overexpression of PtPYRL1 or PtPYRL5 in poplars enhanced the resistance to drought stress, probably by reducing water loss rate.

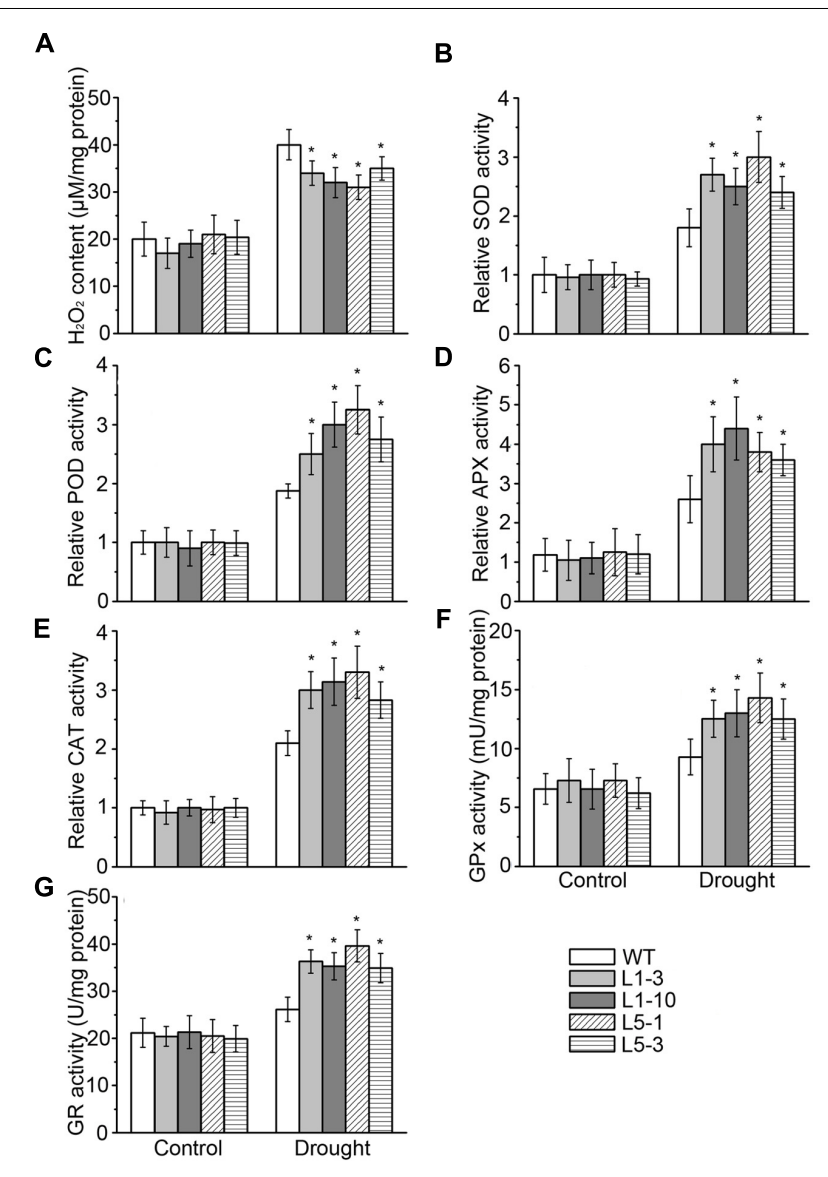

FIGURE $6 \mid \mathrm{H}_{2} \mathrm{O}_{2}$ content (A), SOD (B), POD (C), APX (D), CAT (E), GPX (F), and GR (G) activities assay of WT, PtPYRL 1, and PtPYRL5 overexpressing poplars under drought conditions. 2-month-old WT and transgenic hybrid poplars (L1-3, L1-10, L5-1, and L5-3) were watered regularly, drought stress was performed on these poplars withholding water for additional 5 days, and the leaves were collected. Values for enzyme activities such as SOD, POD, APX, and CAT were normalized to those for the WT hybrid poplars grown under well-watered conditions, which were set at one. Error bars show standard deviations ( $n=12$, one-way ANOVA test; ${ }^{*} P<0.05$ as compared to WT).

\section{Effects of PtPYRLs Overexpression on Antioxidant Metabolism in Poplars under Drought Stress}

Lipid hydroperoxidation is considered as the biochemical indicator of cellular oxidative damage, which is induced by excessive accumulation of the reactive oxidative species (e.g., superoxide and $\mathrm{H}_{2} \mathrm{O}_{2}$ ) in plant cells (Yoshimura et al., 2004; Sochor et al., 2012). Therefore, we measured $\mathrm{H}_{2} \mathrm{O}_{2}$ content in the leaves of WT and transgenic plants. In parallel with the increase in MDA contents indicated in Figure 4, cellular $\mathrm{H}_{2} \mathrm{O}_{2}$ levels were also increased by drought stress in the WT and transgenic PtPYRL1 or PtPYRL5 plants. However, $\mathrm{H}_{2} \mathrm{O}_{2}$ level was significantly lower in these transgenic hybrid poplars than that in the WT leaves (Figure 6A). Correspondingly, the activity of the key enzymes controlling ROS 
scavenging, including superoxide dismutase (SOD), peroxidase (POD), ascorbate peroxidases (APX), and catalase (CAT), were analyzed in these poplars under drought stress. Indeed, the activity of SOD, POD, APX, and CAT were remarkably enhanced in transgenic hybrid poplars compared with the WT (Figures 6B-E). Besides these antioxidant enzymes, plants have several non-enzymatic antioxidants important for redox equilibrium, such as glutathione (GSH) (Cao et al., 2009). GSH content is controlled by glutathione reductase (GR), which has an important role in maintaining the level of glutathione, and by glutathione peroxidases $(\mathrm{GPx})$, which can catalyze the reduction of lipid peroxide through glutathione. Upon drought stress, transgenic hybrid poplars had higher activity of GR and GPx than WT (Figures 6F,G). These results indicated that overexpression of PtPYRL1 and PtPYRL5 resulted in greater stimulation of the activity of enzymes responsible for ROS and GSH metabolism in poplars upon drought stress.

\section{Overexpression of PtPYRL1 or PtPYRL5 Accelerated Stomatal Closure Induced by ABA}

The stomatal movement is one of the most important responses in plants under drought stress, and stomatal behavior is highly controlled by ABA. ABA was thus applied to assess the potential difference in stomatal movement between the WT and the transgenic PtPYRLs poplars. Without any treatment, even though overexpressing lines have more closed stomata, the difference was not significant, as shown by ANOVA test. With $20 \mu \mathrm{M}$ ABA treatment, a significant decrease in stomatal aperture was found for both WT and the transgenic PtPYRLs poplars (Figure 7A). There was a significant difference between WTmock and WT-ABA using ANOVA test. Stomatal apertures in the PtPYRL1- and PtPYRL5-overexpressing lines L1-3, L110 , L5-1, and L5-3 reduced to $0.394,0.395,0.387$, and 0.392, respectively, while stomatal aperture of WT became 0.490 (Figure 7B), which was significantly larger than that of PtPYRL1and PtPYRL5-overexpressing lines. These results indicate that the overexpression of PtPYRL1 and PtPYRL5 enhanced poplar stomatal closure in response to $\mathrm{ABA}$, which might be the cause of the enhanced drought tolerance of transgenic plants.

\section{Overexpression of PtPYRL1 or PtPYRL5 Enhanced Osmotic Stress Resistance}

Osmotic damage is a major consequence of drought stress in plants, and ABA signaling contributes to damage reduction (Skirycz and Inzé, 2010). Overexpression of PtPYRL1 or PtPYRL5 enhanced resistance to water deficit (Figure 3 and Supplementary Figures S3, S4), which suggested a possible role of PtPYRL1 or PtPYRL5 in high osmotic stress resistance. To confirm this possibility, wild-type and transgenic shoots were cultured on 1/2 MS supplemented with 200 or $300 \mathrm{mM}$ mannitol. The supplementation of mannitol inhibited the growth of WT and transgenic poplars (Figure 8A). At the presence of $300 \mathrm{mM}$ mannitol, the WT plants did not even survive and their leaves show yellowish and withered, while young leaves of transgenic plants overexpressing PtPYRL1 or PtPYRL5 kept green and some

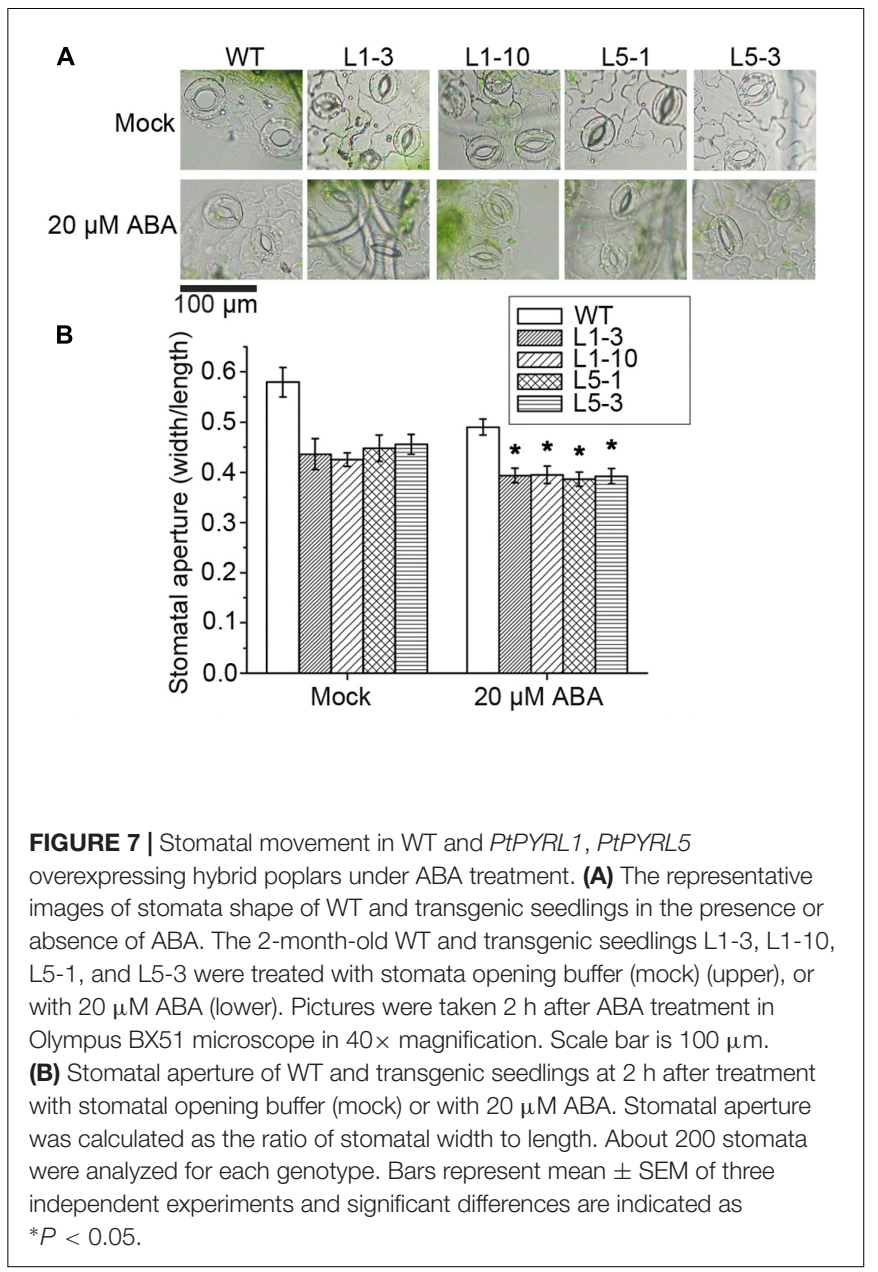

old leaves displayed yellowish at leaf edge (Figures 8A,B). In addition, unlike WT plants, all transgenic plants generated new roots successfully in 1/2 MS medium supplemented with $300 \mathrm{mM}$ mannitol (Figures 8A,B). According to the statistical analysis shown in Figure 8C, transgenic plants overexpressing PtPYRL1 or PtPYRL5 had roots with an average length of around $4.5 \mathrm{~cm}$, while the WT did not have visible roots. These results indicated that the transgenic poplar overexpressing PtPYRL1 or PtPYRL5 improved the resistance to hyperosmotic stress.

\section{Overexpression of PtPYRL1 or PtPYRL5 Reduced the Injury Induced by Low Temperature}

We also subjected WT and transgenic PtPYRL1 or PtPYRL5 poplars to low temperature which is a common stress in poplars growth and found that PtPYRL1 and PtPYRL5 transgenic poplars displayed the increased resistance under chilling stress (Figure 9). After $4^{\circ} \mathrm{C}$ treatment for 5 days, the apical young leaves of WT were damaged more severely with leaf wilting and necrosis than that of transgenic poplars (Figure 9A). Furthermore, the leaves of WT had a higher accumulation of hydrogen peroxide visualized by 3,3-diaminobenzidine (DAB) (Figure 9B). Meanwhile, the 

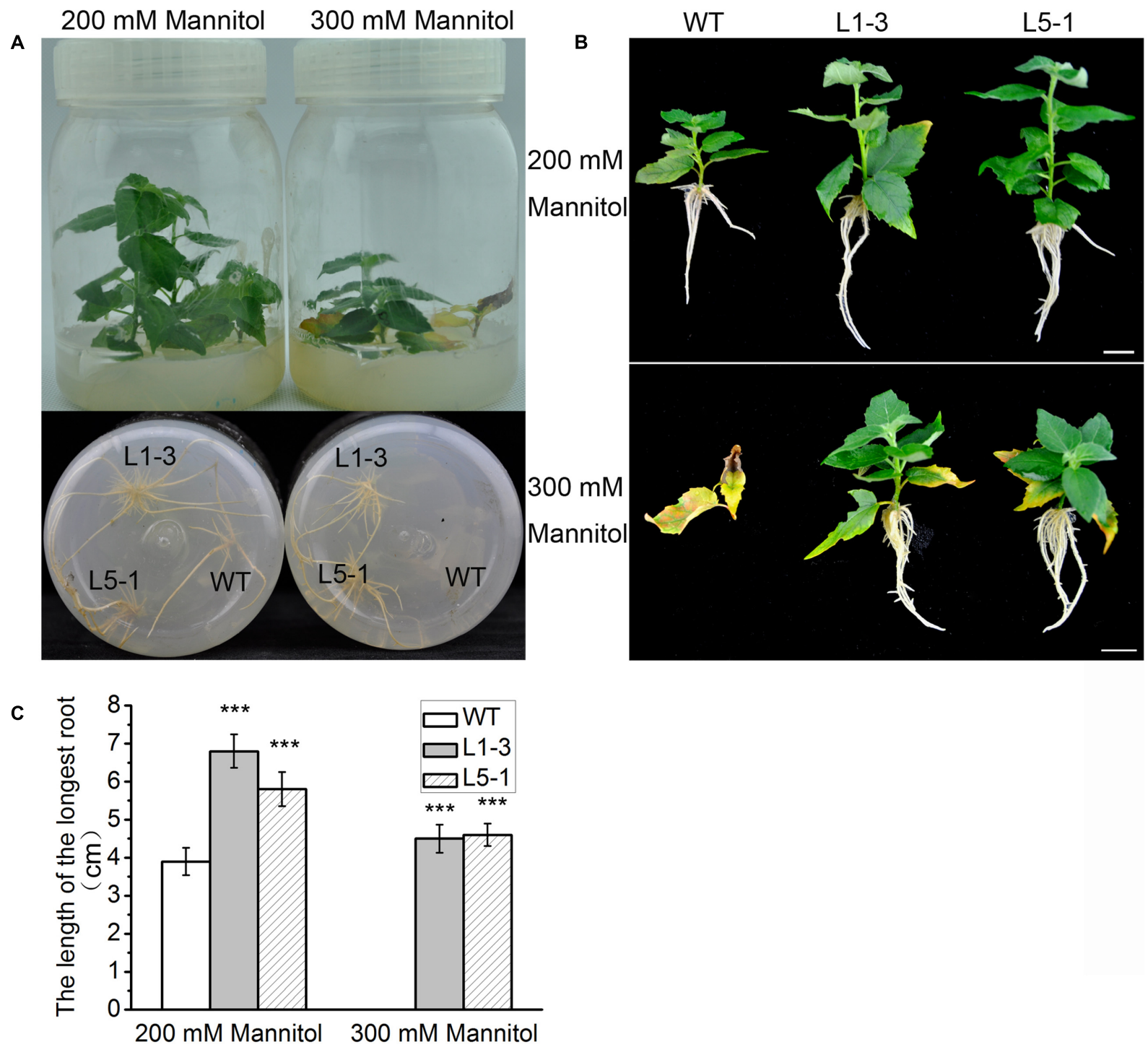

FIGURE 8 | Overexpression of PtPYRL1/5 in hybrid poplar improved resistance to hyperosmotic stress. (A) Short shoot segments (upper) and new fibrous roots (down) grown for 5 days on 1/2 MS medium supplemented with mannitol (200 and $300 \mathrm{mM}$ ). Under 200 and 300 mM mannitol treatment, in comparison to the transgenic poplars, the damage to apical leaves bud and new roots of WT is more serious. (B) Outgrowth of fibrous roots of shoot segments from poplars overexpressing PtPYRL 1/5 (L1-3 and L5-1) is not inhibited by $300 \mathrm{mM}$ mannitol, however, outgrowth of fibrous roots of shoot segments from WT poplars is inhibited by $300 \mathrm{mM}$ mannitol. Bars represent $1 \mathrm{~cm}$. (C) The length of the fibrous root of shoot segments in (B). Values are the mean \pm SD of three independent experiments ( $n=10$ shoots segments, ${ }^{* * *} P<0.001$ as compared to WT).

leaves of WT contained less proline accumulation, a key antifreeze component (Figure 9C). These results suggested that overexpression of PtPYRL1 or PtPYRL5 alleviated the injury induced by low temperature in poplars.

\section{DISCUSSION}

As initial factors in triggering ABA signaling, the physiological function of PYR/PYL/RCARs family is supposed to be critical in the evolution from aquatic to terrestrial plants. PYR/PYL/RCAR genes have been reported to be present as 13-14 members in the genome of Arabidopsis, rice and Populus (Ma et al., 2009; Tian et al., 2015; Yu et al., 2016). As a class of ubiquitous soluble protein, the $P Y R / P Y L / R C A R s$ family plays a critical role in $A B A$ response and signal transduction in plants. Overexpression of Arabidopsis $P Y R / P Y L / R C A R$ receptors is known to enhance ABA response and plant drought tolerance (Santiago et al., 2009; Saavedra et al., 2010; Pizzio et al., 2013). Our previous study showed the transgenic Arabidopsis overexpressing PtPYRL1 or PtPYRL5 were both hypersensitive to ABA and enhanced drought resistance ( $\mathrm{Yu}$ et al., 2016). In the present study, we further provide evidence that these two PtPYRLs are very important in poplars to confer tolerance to diverse environmental 


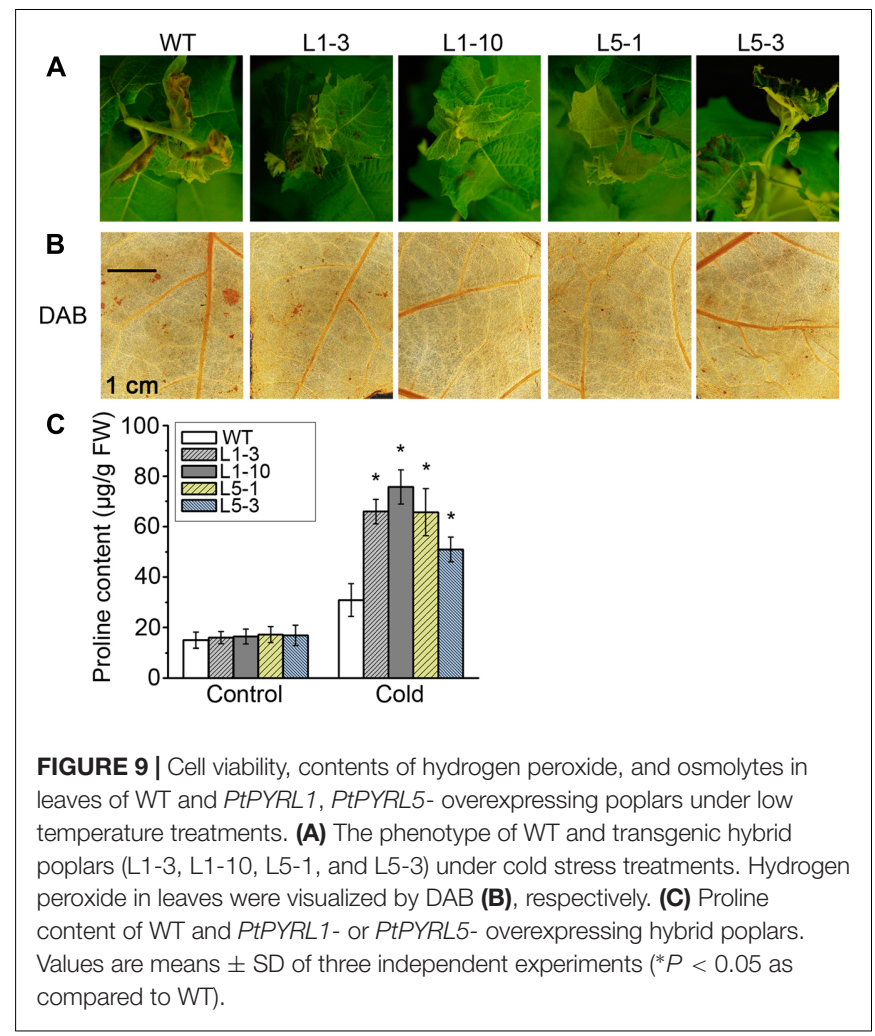

abiotic stresses, including drought, hyper-osmosis, and low temperature.

The $P Y R / P Y L / R C A R$ genes have been shown to enhance drought tolerance in Arabidopsis, rice, and tomato (GonzálezGuzmán et al., 2014; Kim et al., 2014; Zhao et al., 2016). But the evidence of functional studies in the woody plants are still lacking. In our study, hybrid poplar Populus davidiana $\times$ Populus bolleana was transformed with the PtPYRL1 or PtPYRL5 gene and WT hybrid poplar served as control. We did not observe any phenotypic changes in PtPYRL1/5 overexpression transgenic poplars under normal growth conditions. Compared with WT poplars, overexpression of PtPYRL1 or PtPYRL5 enhanced drought tolerance. The shoot weight, leaf water potential, and proline concentration were obviously increased, and MDA content was markedly reduced in transgenic poplars under drought condition, resulted in rapid recovery with higher shoot height after drought and re-watering treatment. Low water availability in the dry soil limited evaporation and made water potential in the cell drop, these changes were associated with reduction in the leaf RWC. The overexpression of PtPYRL1 or PtPYRL5 in poplars showed larger leaf water potential $(\Psi)$ after drought treatment, probably due to increased water retention capacity of the cells, lower water loss rate as well as more adaptive stomatal movement during the stress (Leung and Giraudat, 1998; Zhu, 2002; Souza et al., 2004; Kwak et al., 2008). As showed in Figure 7, exogenous ABA promoted the stomata closure, PtPYRL1 or PtPYRL5 overexpressing transgenic poplars were more sensitive to ABA. Hereafter, recovery will be described as the visual evidence of new above ground development and growth, according to previous studies (Brodribb and Cochard, 2009; Petrov et al., 2015), which defined the process of recovery as a process of reactivated physiological processes and meristematic activity. PtPYRL1 or PtPYRL5 overexpressing transgenic poplars were taller and better recovered than WT poplars after drought and re-watering treatment (Figure 3E). Our findings supported the earlier finding that drought causes hydraulic restriction, with the subsequent development of high tension in the xylem water column and the closure of stomata (Tyree and Sperry, 1988). Larger aboveground biomass indicated better survival in the drought stressed PtPYRL1 or PtPYRL5 overexpressing transgenic poplars, while more proline accumulation resulted in the better water status maintenance (Bajji et al., 2001) and less MDA concentration led to better protection of the cell membrane structures in the drought treated PtPYRL1 or PtPYRL5 overexpressing transgenic poplars. The results presented here indicated that PtPYRL1/5 positively regulates ABA-related response to drought stress.

Drought commonly results in oxidative stress due to the over-production and over-accumulation of ROS derived from inefficient dissipation of excessive excitation energy (Shanker et al., 2014). The over-accumulation of ROS may lead to biochemical disruption of membranes and result in mortality (Suzuki et al., 2012; Petrov et al., 2015). ROS scavenging systems of plants detoxify ROS to minimize and/or prevent oxidative damage in cells by increasing the activity of ROS scavenging enzymes such as SOD, CAT, APX, POD, GR, and GPx (Gill and Tuteja, 2010). In the present study, the content of $\mathrm{H}_{2} \mathrm{O}_{2}$ was significantly lower in the PtPYRL1- and PtPYRL5-overexpressing poplars than in WT under drought stress (Figure 6A). Consistent with this phenomenon, all of the measured antioxidant enzyme activities showed notably increased in transgenic poplars after drought treatment (Figures $\mathbf{6 B}-\mathbf{G}$ ). It was proposed that the antioxidant protection is related to higher leaf water potential $\Psi$ (Figure 3F and Supplementary Figures S3F, S4F) (Menconi et al., 1995). These results demonstrated that overexpression of PtPYRL1 or PtPYRL5 increased the antioxidant enzyme activities protecting transgenic poplars against the oxidative damage.

Consistently, osmotic stress significantly suppressed wildtype poplars roots development and leaf growth compared with PtPYRL1 or PtPYRL5 overexpressing poplars (Figure 8). The increased root growth rate of transgenic poplars (Figure $\mathbf{8 C}$ ) has to be coupled with a mechanism that alleviates the physiological growth retardation consequences of the osmotic stress. In PtPYRL1 or PtPYRL5 overexpressing poplars, roots had increased the low water availability, as their rapid root growth resulted in more water absorption. Since the osmotic stress has been suggested to increase the ABA levels in plant cells (Zeevaart and Creelman, 1998), transgenic poplars might perceive ABA more rapidly and might trigger more efficiently the downstream responses. The phenotype of transgenic poplars under osmotic stress indicated that PtPYRL1 or PtPYRL5 increased the tolerance to hyperosmotic stress.

Another common environmental stress, a low temperature, severely inhibits plant growth and development. A recent study illustrated that co-overexpression of two genes, a bZIP 
transcription factor (OsbZIP46CA1) and a protein kinase (SAPK6) involved in the ABA signaling pathway, showed improved tolerance to heat and cold stresses in rice (Chang et al., 2017). In order to enhance plant adaptability to low temperature, lipids, amino acid, membrane components, and other molecules in the cell are produced to promote cell membrane fluidity and structural rearrangement (Maruyama et al., 2014; Wu et al., 2016). Balance of the cellular ROS homeostasis also contributes to the tolerance to temperature stresses (Wang et al., 2017). Our results showed that the PtPYRL1 or PtPYRL5 overexpressing poplars enhanced low temperature stress tolerance (Figure 9), associated with more efficient ROS scavenging (Figure 9B) and more proline accumulation to maintain membrane integrity (Figure 9C). On the other hand, it is well known that phytohormone ABA activates a cascade of downstream signaling events in response to cold exposure (Knight et al., 2004). Further studies are required to investigate how PtPYRL1 and PtPYRL5 mediates adaptive responses to cold at the molecular level. Moreover, though our data showed that both $\mathrm{ABA}$ receptors are over-expressed in transgenic poplar plants at the mRNA level, it would be interesting to test their protein accumulation in future studies, since it has been suggested that PYR/PYL receptors undergo regulation at protein level by $26 \mathrm{~S}$ proteasome pathway in Arabidopsis (Bueso et al., 2014; Irigoyen et al., 2014).

Populus is a perennial woody model plant and also economically important tree. Most Populus are sensitive to environmental factors, which considerably affects their productivities. As we know, arid and semi-arid regions account for approximately $30 \%$ of the worldwide area (Sivakumar et al., 2005). Meanwhile, the climate in poplars cultivated land of China is mostly dry and frigid. Therefore, breeding high drought- and cold-tolerant poplar cultivars is very necessary for improving land use efficiency and poplar forestry development. In our study, transgenic poplar overexpressing PtPYRL1 or PtPYRL5 was found to be significantly more drought and chilling tolerant than WT plants. We hope that the transgenic poplars generated in this study can be used for cultivating in cold as well as arid and semi-arid areas.

\section{AUTHOR CONTRIBUTIONS}

LY, RT, and SL designed the study. LY, WL, HG, and JY revised the manuscript critically. LY, JY, RT, YW, XW, and FZ performed

\section{REFERENCES}

Allen, G. J., Kuchitsu, K., Chu, S. P., Murata, Y., and Schroeder, J. I. (1999). Arabidopsis abi1-1 and abi2-1 phosphatase mutations reduce abscisic acidinduced cytoplasmic calcium rises in guard cells. Plant Cell 11, 1785-1798. doi: $10.2307 / 3871054$

Apel, K., and Hirt, H. (2004). Reactive oxygen species: metabolism, oxidative stress, and signal transduction. Annu. Rev. Plant Biol. 55, 373-399. doi: 10.1146/ annurev.arplant.55.031903.141701

Bajji, M., Kinet, J.-M., and Lutts, S. (2001). The use of the electrolyte leakage method for assessing cell membrane stability as a water stress tolerance test in durum wheat. Plant Growth Regul. 36, 61-70. doi: 10.1023/A:1014732714549 experiments, analyzed and interpreted the data, and wrote the manuscript.

\section{FUNDING}

This study was supported by the Fundamental Research Funds for the Central Universities (020814380062) and the Natural Science Foundation of Jiangsu Province of China (BK2012306).

\section{ACKNOWLEDGMENT}

We gratefully acknowledge Hongxia Zhang for poplar material and pCAMBIA1301S2 plasmid.

\section{SUPPLEMENTARY MATERIAL}

The Supplementary Material for this article can be found online at: https://www.frontiersin.org/articles/10.3389/fpls.2017.01752/ full\#supplementary-material

FIGURE S1 | The PCAMBIA1301S2-PtPYRL1 (or PtPYRL5) Vector map.

FIGURE S2 | Transformants selection. (A) Adventitious bud regenerated from selection medium. (B) Transgenic shoots formed roots on selection medium.

FIGURE S3 | Overexpression of poplar ABA receptor PtPYRL5 in poplars enhanced drought-stress resistance. (A) 2-month-old WT (non-transgenic hybrid poplars) and transgenic poplars (L5-1 and L5-3) were cultured in the greenhouse with normal watering. (B) WT and transgenic hybrid poplars were not watered for 5 days. (C) After drought, WT and transgenic hybrid poplars were then re-watered for 3 days. The shoot weight after drought stress treatment (D), shoot height after re-watered for 3 days (E), water potential value (F) of WT and transgenic hybrid poplars were measured. Values are means \pm SD (one-way ANOVA test; ${ }^{*} P<0.05$ as compared to WT).

FIGURE S4 | Overexpression of poplar ABA receptor PtPYRL1 in poplars enhanced drought-stress resistance. (A) 2-month-old WT (non-transgenic hybrid poplars) and transgenic poplars (L1-8 and L1-5) were cultured in the greenhouse with normal watering. (B) WT and transgenic hybrid poplars were not watered for 5 days. (C) After drought, WT and transgenic hybrid poplars were then re-watered for 3 days. The shoot weight after drought stress treatment (D), shoot height after re-watered for 3 days $(\mathbf{E})$, water potential value $(\mathbf{F})$, proline content $(\mathbf{G})$ and MDA content $\mathbf{( H )}$ of WT and transgenic hybrid poplars were measured. Values are means $\pm \mathrm{SD}$ ( $n=18$, three independent experiments, one-way ANOVA test; $* P<0.05)$.

Bates, T. R., Rosenberg, H. A., and Tembo, A. V. (1973). Inconsistencies in rationale underlying official USP dissolution rate specifications for nitrofurantoin. J. Pharm. Sci. 62, 2057-2058. doi: 10.1002/jps.260062 1241

Brodribb, T. J., and Cochard, H. (2009). Hydraulic failure defines the recovery and point of death in water-stressed conifers. Plant Physiol. 149, 575-584. doi: $10.1104 /$ pp.108.129783

Bueso, E., Rodriguez, L., Lorenzo-Orts, L., Gonzalez-Guzman, M., Sayas, E., Muñoz-Bertomeu, J., et al. (2014). The single-subunit RING-type E3 ubiquitin ligase RSL1 targets PYL4 and PYR1 ABA receptors in plasma membrane to modulate abscisic acid signaling. Plant J. 80, 1057-1071. doi: 10.1111/tpj. 12708 
Cao, Y., Zhang, Z. W., Xue, L. W., Du, J. B., Shang, J., Xu, F., et al. (2009). Lack of salicylic acid in Arabidopsis protects plants against moderate salt stress. Z. Naturforsch. C 64, 231-238. doi: 10.1515/znc-2009-3-414

Carlberg, I., and Mannervik, B. (1985). Glutathione reductase. Methods Enzymol. 113, 484-490. doi: 10.1016/S0076-6879(85)13062-4

Chance, M., and Maehly, A. C. (1955). The assay of catalases and peroxidases. Methods Enzymol. 2, 764-817. doi: 10.1016/S0076-6879(55)02300-8

Chang, Y., Nguyen, B. H., Xie, Y., Xiao, B., Tang, N., Zhu, W., et al. (2017). Co-overexpression of the constitutively active form of OsbZIP46 and ABAactivated protein kinase SAPK6 improves drought and temperature stress resistance in rice. Front. Plant Sci. 8:1102. doi: 10.3389/fpls.2017.01102

Contreras-Porcia, L., Thomas, D., Flores, V., and Correa, J. A. (2011). Tolerance to oxidative stress induced by desiccation in Porphyra columbina (Bangiales, Rhodophyta). J. Exp. Bot. 62, 1815-1829. doi: 10.1093/jxb/erq364

Doty, S. L., Sher, A. W., Fleck, N. D., Khorasani, M., Bumgarner, R. E., Khan, Z., et al. (2016). Variable nitrogen fixation in wild Populus. PLOS ONE 11:e0155979. doi: 10.1371/journal.pone.0155979

Finkelstein, R. R., Gampala, S. S., and Rock, C. D. (2002). Abscisic acid signaling in seeds and seedlings. Plant Cell 14(Suppl.), S15-S45. doi: 10.1105/tpc.010441

Fujii, H., Verslues, P. E., and Zhu, J. K. (2007). Identification of two protein kinases required for abscisic acid regulation of seed germination, root growth, and gene expression in Arabidopsis. Plant Cell 19, 485-494. doi: 10.1105/tpc.106.048538

Giannopolitis, C. N., and Ries, S. K. (1977). Superoxide dismutases occurrence in higher plants. Plant Physiol. 59, 309-314. doi: 10.1104/pp.59.2.309

Gill, S. S., and Tuteja, N. (2010). Reactive oxygen species and antioxidant machinery in abiotic stress tolerance in crop plants. Plant Physiol. Biochem. 48, 909-930. doi: 10.1016/j.plaphy.2010.08.016

Gonzalez-Guzman, M., Pizzio, G. A., Antoni, R., Vera-Sirera, F., Merilo, E., Bassel, G. W., et al. (2012). Arabidopsis PYR/PYL/RCAR receptors play a major role in quantitative regulation of stomatal aperture and transcriptional response to abscisic acid. Plant Cell 24, 2483-2496. doi: 10.1105/tpc.112.098574

González-Guzmán, M., Rodríguez, L., Lorenzo-Orts, L., Pons, C., SarriónPerdigones, A., Fernández, M. A., et al. (2014). Tomato PYR/PYL/RCAR abscisic acid receptors show high expression in root, differential sensitivity to the abscisic acid agonist quinabactin, and the capability to enhance plant drought resistance. J. Exp. Bot. 65, 4451-4464. doi: 10.1093/jxb/eru219

Heath, R. L., and Packer, L. (1968). Photoperoxidation in isolated chloroplasts. I. Kinetics and stoichiometry of fatty acid peroxidation. Arch. Biochem. Biophys. 125, 189-198. doi: 10.1016/0003-9861(68)90654-1

Himmelbach, A., Yang, Y., and Grill, E. (2003). Relay and control of abscisic acid signaling. Curr. Opin. Plant Biol. 6, 470-479. doi: 10.1016/S1369-5266(03) 00090-6

Hu, L., Li, H., Pang, H., and Fu, J. (2012). Responses of antioxidant gene, protein and enzymes to salinity stress in two genotypes of perennial ryegrass (Lolium perenne) differing in salt tolerance. J. Plant Physiol. 169, 146-156. doi: 10.1016/ j.jplph.2011.08.020

Irigoyen, M. L., Iniesto, E., Rodriguez, L., Puga, M. I., Yanagawa, Y., Pick, E., et al. (2014). Targeted degradation of abscisic acid receptors is mediated by the ubiquitin ligase substrate adaptor DDA1 in Arabidopsis. Plant Cell 26, 712-728. doi: $10.1105 /$ tpc.113.122234

Jefferson, R. A., Kavanagh, T. A., and Bevan, M. W. (1987). GUS fusions: betaglucuronidase as a sensitive and versatile gene fusion marker in higher plants. EMBO J. 6, 3901-3907.

Jiang, M., and Zhang, J. (2002). Role of abscissic acid in water stress-induced antioxidant defense in leaves of maize seedlings. Free Radic. Res. 36, 1001-1015. doi: 10.1080/1071576021000006563

Kim, H., Lee, K., Hwang, H., Bhatnagar, N., Kim, D. Y., Yoon, I. S., et al. (2014). Overexpression of PYL5 in rice enhances drought tolerance, inhibits growth, and modulates gene expression. J. Exp. Bot. 65, 453-464. doi: 10.1093/jxb/ert397

Knight, H., Zarka, D. G., Okamoto, H., Thomashow, M. F., and Knight, M. R. (2004). Abscisic acid induces $C B F$ gene transcription and subsequent induction of cold-regulated genes via the CRT promoter element. Plant Physiol. 135, 1710-1717. doi: 10.1104/pp.104.043562

Kwak, J. M., Mäser, P., and Schroeder, J. I. (2008). The clickable guard cell, version II: interactive model of guard cell signal transduction mechanisms and pathways. Arabidopsis Book 6:e0114. doi: 10.1199/tab.0114

Lackman, P., González-Guzmán, M., Tilleman, S., Carqueijeiro, I., Pérez, A. C., Moses, T., et al. (2011). Jasmonate signaling involves the abscisic acid receptor
PYL4 to regulate metabolic reprogramming in Arabidopsis and tobacco. Proc. Natl. Acad. Sci. U.S.A. 108, 5891-5896. doi: 10.1073/pnas.1103010108

Lee, S. C., Lan, W. Z., Buchanan, B. B., and Luan, S. (2009). A protein kinasephosphatase pair interacts with an ion channel to regulate ABA signaling in plant guard cells. Proc. Natl. Acad. Sci. U.S.A. 106, 21419-21424. doi: 10.1073/ pnas.0910601106

Leung, J., and Giraudat, J. (1998). Abscisic acid signal transduction. Annu. Rev. Plant Physiol Plant Mol. Biol. 49, 199-222. doi: 10.1146/annurev.arplant.49. 1.199

Liu, C. C., Liu, Y. G., Guo, K., Fan, D. Y., Li, G. Q., Zheng, Y. R., et al. (2011). Effect of drought on pigments, osmotic adjustment and antioxidant enzymes in six woody plant species in karst habitats of southwestern China. Environ. Exp. Bot. 71, 174-183. doi: 10.1016/j.envexpbot.2010.11.012

Liu, X., Yue, Y., Li, B., Nie, Y., Li, W., Wu, W. H., et al. (2007). A G protein-coupled receptor is a plasma membrane receptor for the plant hormone abscisic acid. Science 315, 1712-1716. doi: 10.1126/science.1135882

Liu, Y., Pan, Z., Zhuang, Q., Miralles, D. G., Teuling, A. J., Zhang, T., et al. (2015). Agriculture intensifies soil moisture decline in Northern China. Sci. Rep. 5:11261. doi: 10.1038/srep11261

Ma, Y., Szostkiewicz, I., Korte, A., Moes, D., Yang, Y., Christmann, A., et al. (2009). Regulators of PP2C phosphatase activity function as abscisic acid sensors. Science 324, 1064-1068. doi: 10.1126/science. 1172408

Maehly, A. C., and Chance, B. (1954). The assay of catalases and per regulators of PP2C phosphatase activity function as abscisic acid sensors oxidases. Methods Biochem. Anal. 1, 357-424.

Maruyama, K., Urano, K., Yoshiwara, K., Morishita, Y., Sakurai, N., Suzuki, H., et al. (2014). Integrated analysis of the effects of cold and dehydration on rice metabolites, phytohormones, and gene transcripts. Plant Physiol. 164, 1759-1771. doi: 10.1104/pp.113.231720

Menconi, M., Sgherri, C. L. M., Pinzino, C., and Navari-Izzo, F. (1995). Activated oxygen production and detoxification in wheat plants subjected to a water deficit programme. J. Exp. Bot. 46, 1123-1130. doi: 10.1093/jxb/46.9. 1123

Mustilli, A. C., Merlot, S., Vavasseur, A., Fenzi, F., and Giraudat, J. (2002). Arabidopsis OST1 protein kinase mediates the regulation of stomatal aperture by abscisic acid and acts upstream of reactive oxygen species production. Plant Cell 14, 3089-3099. doi: 10.1105/tpc.007906

Nakano, Y., and Asada, K. (1981). Hydrogen peroxide is scavenged by ascorbatespecific peroxidase in spinach chloroplasts. Plant Cell Physiol. 22, 867-880.

Pandey, S., Nelson, D. C., and Assmann, S. M. (2009). Two novel GPCR-type $\mathrm{G}$ proteins are abscisic acid receptors in Arabidopsis. Cell 136, 136-148. doi: 10.1016/j.cell.2008.12.026

Park, S. Y., Fung, P., Nishimura, N., Jensen, D. R., Fujii, H., Zhao, Y., et al. (2009). Abscisic acid inhibits type $2 \mathrm{C}$ protein phosphatases via the PYR/PYL family of START proteins. Science 324, 1068-1071. doi: 10.1126/science.1173041

Petrov, V., Hille, J., Mueller-Rueber, B., and Gechev, T. (2015). ROS-mediated abiotic-stress induced programmed cell death in plants. Front. Plant Sci. 6:69. doi: 10.3389/fpls.2015.00069

Pizzio, G. A., Rodriguez, L., Antoni, R., Gonzalez-Guzman, M., Yunta, C., Merilo, E., et al. (2013). The PYL4 A194T mutant uncovers a key role of PYR1LIKE4/PROTEIN PHOSPHATASE 2CA interaction for abscisic acid signaling and plant drought resistance. Plant Physiol. 163, 441-455. doi: 10.1104/pp.113. 224162

Saavedra, X., Modrego, A., Rodríguez, D., González-García, M. P., Sanz, L., Nicolás, G., et al. (2010). The nuclear interactor PYL8/RCAR3 of Fagus sylvatica FsPP2C1 is a positive regulator of abscisic acid signaling in seeds and stress. Plant Physiol. 152, 133-150. doi: 10.1104/pp.109.146381

Santiago, J., Rodrigues, A., Saez, A., Rubio, S., Antoni, R., Dupeux, F., et al. (2009). Modulation of drought resistance by the abscisic acid receptor PYL5 through inhibition of clade A PP2Cs. Plant J. 60, 575-588. doi: 10.1111/j.1365-313X. 2009.03981.x

Seki, M., Ishida, J., Narusaka, M., Fujita, M., Nanjo, T., Umezawa, T., et al. (2002). Monitoring the expression pattern of around 7,000 Arabidopsis genes under $\mathrm{ABA}$ treatments using a foil-length cDNA microarray. Funct. Integr. Genomics 2, 282-291. doi: 10.1007/s10142-002-0070-6

Shanker, A. K., Maheswari, M., Yadav, S. K., Desai, S., Bhanu, D., Attal, N. B., et al. (2014). Drought stress responses in crops. Funct. Integr. Genomics 14, 11-22. doi: $10.1007 / \mathrm{s} 10142-013-0356-\mathrm{x}$ 
Shen, Y. Y., Wang, X. F., Wu, F. Q., Du, S. Y., Cao, Z., Shang, Y., et al. (2006). The Mg-chelatase $\mathrm{H}$ subunit is an abscisic acid receptor. Nature 443, 823-826. doi: $10.1038 /$ nature05176

Sivakumar, M. V. K., Das, H. P., and Brunini, O. (2005). Impacts of present and future climate variability and change on agriculture and forestry in the arid and semi-arid tropics. Clim. Change 70, 31-72. doi: 10.1007/s10584-0055937-9

Skirycz, A., and Inzé, D. (2010). More from less: plant growth under limited water. Curr. Opin. Biotechnol. 21, 197-203. doi: 10.1016/j.copbio.2010. 03.002

Sochor, J., Ruttkay-Nedecky, B., Babula, P., Adam, V., Hubalek, J., and Kizek, R. (2012). "Automation of methods for determination of lipid peroxidation," in Lipid Peroxidation, ed. A. Catala (Rijeka: In Tech).

Souza, R. P., Machado, E. C., Silva, J. A. B., Lagôa, A. M. M. A., and Silveira, J. A. G. (2004). Photosynthetic gas exchange, chlorophyll fluorescence and some associated metabolic changes in cowpea (Vigna unguiculata) during water stress and recovery. Environ. Exp. Bot. 51, 45-56. doi: 10.1016/S0098-8472(03)00 059-5

Štajner, D., Orlovic, S., Popovic, B., Kebert, M., and Galic, Z. (2011). Screening of drought oxidative stress tolerance in Serbian melliferous plant species. Afr. J. Biotechnol. 10, 1609-1614.

Suzuki, N., Koussevitzky, S., Mittler, R., and Miller, G. (2012). ROS and redox signaling in the response of plants to abiotic stress. Plant Cell Environ. 35, 259-270. doi: 10.1111/j.1365-3040.2011.02336.x

Tian, X., Wang, Z., Li, X., Lv, T., Liu, H., Wang, L., et al. (2015). Characterization and functional analysis of pyrabactin resistance-like abscisic acid receptor family in rice. Rice 8, 28. doi: 10.1186/s12284-015-0061-6

Tyree, M. T., and Sperry, J. S. (1988). Do woody plants operate near the point of catastrophic xylem dysfunction caused by dynamic water stress? Answers from a model. Plant Physiol. 88, 547-580. doi: 10.1104/pp.88.3.574

Wang, J., Wu, B., Yin, H., Fan, Z., Li, X., Ni, S., et al. (2017). Overexpression of CaAPX induces orchestrated reactive oxygen scavenging and enhances cold and heat tolerances in tobacco. Biomed Res. Int. 2017:4049534. doi: 10.1155/2017/ 4049534

Wu, Z. G., Jiang, W., Chen, S. L., Mantri, N., Tao, Z. M., and Jiang, C. X. (2016). Insights from the cold transcriptome and metabolome of Dendrobium officinale: global reprogramming of metabolic and gene regulation networks during cold acclimation. Front. Plant Sci. 7:1653. doi: 10.3389/fpls.2016.01653
Yang, Y., Qi, M., and Mei, C. (2004). Endogenous salicylic acid protects rice plants from oxidative damage caused by aging as well as biotic and abiotic stress. Plant J. 40, 909-919. doi: 10.1111/j.1365-313X.2004.02267.x

Yoshida, R., Hobo, T., Ichimura, K., Mizoguchi, T., Takahashi, F., Aronso, J., et al. (2002). ABA-activated SnRK2 protein kinase is required for dehydration stress signaling in Arabidopsis. Plant Cell Physiol. 43, 1473-1483. doi: 10.1093/pcp/ pcf188

Yoshimura, K., Miyao, K., Gaber, A., Takeda, T., Kanaboshi, H., Miyasaka, H., et al. (2004). Enhancement of stress tolerance in transgenic tobacco plants overexpressing Chlamydomonas glutathione peroxidase in chloroplasts or cytosol. Plant J. 37, 21-33. doi: 10.1046/j.1365-313X.2003.01930.x

Yu, J. L., Yang, L., Liu, X., Tang, R. J., Wang, Y., Ge, H. M., et al. (2016). Overexpression of poplar pyrabactin resistance-like abscisic acid receptors promotes abscisic acid sensitivity and drought resistance in transgenic Arabidopsis. PLOS ONE 11:e0168040. doi: 10.1371/journal.pone.0168040

Zeevaart, J. A. D., and Creelman, R. A. (1998). Metabolism and physiology of abscisic acid. Annu. Rev. Plant Physiol. Plant Mol. Biol. 39, 439-473. doi: 10.1146/annurev.pp.39.060188.002255

Zhao, Y., Chan, Z., Gao, J., Xing, L., Cao, M., Yu, C., et al. (2016). ABA receptor PYL9 promotes drought resistance and leaf senescence. Proc. Natl. Acad. Sci. U.S.A. 113, 1949-1954. doi: 10.1073/pnas.1522840113

Zhou, L., Wang, S., Chi, Y., Li, Q., Huang, K., and Yu, Q. (2015). Responses of photosynthetic parameters to drought in subtropical forest ecosystem of China. Sci. Rep. 5:18254. doi: 10.1038/srep 18254

Zhu, J. K. (2002). Salt and drought stress signal transduction in plants. Annu. Rev. Plant Biol. 53, 247-273. doi: 10.1146/annurev.arplant.53.091401.143329

Conflict of Interest Statement: The authors declare that the research was conducted in the absence of any commercial or financial relationships that could be construed as a potential conflict of interest.

Copyright (c) 2017 Yu, Ge, Wang, Tang, Wang, Zhao, Lan, Luan and Yang. This is an open-access article distributed under the terms of the Creative Commons Attribution License (CC BY). The use, distribution or reproduction in other forums is permitted, provided the original author(s) or licensor are credited and that the original publication in this journal is cited, in accordance with accepted academic practice. No use, distribution or reproduction is permitted which does not comply with these terms. 